\title{
Utilizando games para ensinar Ciências: percepções de estudantes do Ensino Fundamental
}

\author{
Gisele Soares Lemos Shaw ${ }^{1}$ \\ Marcelo Silva de Souza Ribeiro ${ }^{2}$ \\ João Batista Teixeira da Rocha ${ }^{3}$
}

\begin{abstract}
RESUMO
Dentre as diversas TIC empregadas atualmente, o uso de games tem sido uma possibilidade interessante, pois pode dar novos sentidos ao uso do computador e gerar aprendizagem. Este artigo é fruto de uma pesquisa qualitativa e envolve a investigação das potencialidades da utilização de três games no processo de ensino-aprendizagem do conteúdo sistemas do corpo humano, nas percepções de uma professora e estudantes de sétima série do Ensino Fundamental. Os dados foram coletados por meio de observação, questionários, entrevistas individuais e entrevistas em grupo focal. Para os estudantes, o uso de games no ensino de ciências auxilia na motivação, facilita a compreensão dos conteúdos, além de ser algo divertido, dinâmico e que reduz a indisciplina em classe. Considera-se as contribuições positivas desses games à aprendizagem de ciências, mas aponta-se efeitos negativos, tais como ansiedade e nervosismo nos jogadores.
\end{abstract}

PALAVRAS-CHAVE: Aprendizagem. Games. Motivação.

Using games to learn science: student perceptions of Elementary

\section{Education}

${ }_{1}^{1}$ Doutorado em Educação e ensino de ciências. Universidade Federal do Vale do São Francisco (UNIVASF), Senhor do Bonfim, Bahia, Brasil. E-mail: giseleshaw@hotmail.com ${ }^{2}$ Doutorado em Ciências da Educação. Universidade Federal do Vale do São Francisco (UNIVASF), Petrolina, Pernambuco, Brasil. E-mail: marcelo.ribeiro@univasf.edu.br ${ }^{3}$ Doutorado em Ciências Biológicas (Bioquímica). Universidade Federal de Santa Maria (UFSM), Santa Maria, Rio Grande do Sul, Brasil. E-mail: jbtrocha@yahoo.com.br 


\begin{abstract}
Among the various ICTs currently used, the use of games has been an interesting possibility, since it can give new meanings to the use of the computer and generate learning. This article is the result of a qualitative research and involves the investigation of the potentialities of the use of three games in the teaching-learning process of the content systems of the human body, in the perceptions of a teacher and seventh grade elementary students. We collected data through observation, questionnaires, individual interviews and focus group interviews. For students, the use of games in science education helps motivation, eases understanding of the contents, and is fun, dynamic and reduces class indiscipline. It is important to consider the positive contributions of these games to learning science, but also to investigate possible adverse effects, such as anxiety and nervousness in the players.
\end{abstract}

KEYWORDS: Games. Learning in sciences. Motivation.

$$
* * *
$$

\title{
Introdução
}

O advento das Tecnologias de Informação e Comunicação (TIC) aplicadas à educação leva à reflexão sobre a necessidade de criar estratégias que possam envolver alunos, professores e, se possível, toda comunidade escolar, como demais técnicos e auxiliares da escola, além da família (MORAES, 2004; TAJRA, 2002). A ideia é que esse envolvimento traga resultados positivos a essa comunidade e culmine numa inserção das TIC na própria cultura da escola.

Dentre as diversas TIC empregadas atualmente, o uso do computador na educação tem sido uma possibilidade interessante para o envolvimento de alunos em atividades de ensino. De acordo com Pretto e Pinto (2006), o desenvolvimento de técnicas computacionais, tais como os games e a simulação, proporcionaram novos sentidos ao uso do computador, que passou a ser um instrumento propiciador de desenvolvimento do 
pensamento e criatividade. Esse processo contribuiu com a socialização de saberes que passaram a ser disseminados pela rede. Conforme Levy (1999), isso gerou a criação de uma inteligência coletiva, em um ciberespaço. Para Pretto e Pinto (2006), a utilização de softwares livres tem sido propiciadora dessa rede colaborativa e criadora de cultura, ensejando o processo criativo/interativo, além de permitir, assim, uma real inclusão digital.

Os softwares do tipo game apresentam a vantagem de que, além de permitir esse processo interativo, também são mais motivadores e articulados a uma aprendizagem mais significativa. Para Fialho e Matos (2010), games são softwares que possibilitam aprender brincando, além da aprendizagem de regras que, segundo Alves (2010), envolvem elementos do tipo "o raciocínio lógico, a criatividade, a atenção, a capacidade de solucionar problemas, a visão estratégica e, principalmente, o desejo de vencer" (p.211). Eles explicam que os games permitem reprodução de fenômenos reais que dão aos alunos uma qualidade superior de realismo em seu aprendizado. Além disso, a utilização de games no ensino, do tipo que simulam situações e fenômenos, tem como função:

dar possibilidades ao aluno de desenvolver e testar hipóteses, analisar resultados, intervir e envolver-se, chegando às suas próprias conclusões de forma lúdica e autônoma, mesclando simulações e jogos num enriquecimento ímpar do processo de ensino/aprendizagem (FIALHO; MATOS, 2010, p.129).

Diante dessas contribuições de games no processo de ensino e aprendizagem, por meio de uma pesquisa de natureza qualitativa, desenvolvida numa escola de Educação Básica do município de Senhor do Bonfim, Bahia, foram investigadas as potencialidades de uso de três games (Code Fred, Simon Cérebro e Comando Imuno) no processo de ensinoaprendizagem de sistemas do corpo humano. Além disso, objetivou-se a facilitação de processos de ensino e aprendizagem, envolvendo alunos da $7^{\mathrm{a}}$ 
série, no que tange ao conteúdo escolar de um modo mais interativo, lúdico e próximo de uma linguagem comum geração desses jovens, ou seja, uma linguagem digital. Neste trabalho, portanto, com base nas potencialidades dos games na educação, por meio de observação direta, questionários e entrevistas, buscou-se apresentar percepções de alunos de duas turmas sobre as contribuições da utilização de softwares livres desse tipo para o ensino e a aprendizagem de Ciências. Em outros trabalhos apresentamos demais aspectos da experiência ${ }^{4}$, além das percepções dos estudantes, que são elementos importantes para entender a situação em questão, em comparação a trabalhos na mesma linha de investigação.

\section{Os games na educação: alguns estudos recentes}

Pesquisas recentes apontaram que a inserção de TIC no ensino, tais como a utilização de games, é uma tendência. Os games são utilizados como uma maneira de atrair os estudantes e motivá-los a aprender conteúdos curriculares.

Shimohara, Sobreira e Ito (2016) analisaram a avaliação de jogos digitais de matemática por três turmas de estudantes do quinto ano do Ensino Fundamental. Segundo os autores, os estudantes participantes da pesquisa programaram seus jogos e os avaliaram entre si. A investigação buscou atender a teoria do GameFlow, criada por Sweetser e Wyeth. Segundo Shimohara, Sobreira e Ito (2016), essa teoria partiu dos estudos do psicólogo húngaro Mihaly Csikszentmihalyi, que investigou quais são os aspectos que trazem sensação de felicidade nas pessoas. Segundo Sweetser e Wyeth, a teoria do GameFlow avalia o nível de prazer propiciada pelo game ao usuário, pois investiga o equilíbrio entre as habilidades do jogador e os desafios das tarefas executadas. Para eles, o alcance desse equilíbrio representa o estado de "flow", ou seja, de satisfação do usuário do game.

\footnotetext{
${ }^{4}$ Ver outras discussões sobre a experiência em Shaw (2014), Shaw e Ribeiro (2014) e em Shaw, Ribeiro e Rocha (2014).
} 
Neves e colaboradores (2014) trataram do GameFlow como um método que, "consiste em 35 heurísticas distribuídas nas seguintes áreas: concentração, desafio, imersão, interação social, habilidades do jogador, controle, objetivos claros e feedback" (p.45) ${ }^{5}$. Na perspectiva do Game Flow, o game deve ser divertido o suficiente para levar o jogador a se concentrar e deve ser desafiador o suficiente para que o estimule sem que desperte ansiedade. O jogo deve levar o jogador a desenvolver suas habilidades gradualmente, num mecanismo de desafio e recompensa, no qual ele sinta controle sobre o jogo, o que pode induzir o participante ao estado de flow, de prazer. Também, o jogo precisa apresentar seus objetivos de modo claro e, no momento certo, permitir a imersão do jogador na história do jogo. Enquanto joga, o participante precisa ter ciência do que está acontecendo e do que vai ocorrer, de seus progressos e o jogo é que deve propiciar esse entendimento, o que pode gerar envolvimento emocional no jogador e até vontade de dialogar com outros jogadores sobre a experiência (NEVES, et al. 2014).

Entretanto, é preciso destacar que, no que tange a jogos utilizados para ensino, é preciso que o conteúdo explorado no game envolva o estudante para além do ato de jogar, o jogo tem que atrair o estudante ao processo de interação com o game de modo a mobilizá-lo ao estudo, colocando, assim, a aprendizagem do conteúdo como objetivo principal. Importante, contudo, salientar que a motivação gerada no estudante pela utilização do game na aula não é garantia da aprendizagem dos conteúdos trabalhados (GARCEZ; SOARES, 2017).

Para que os estudantes avaliassem os jogos, Shimohara, Sobreira e Ito (2016), utilizaram os seguintes parâmetros: concentração e tempo de jogo, desafio, habilidade do jogador, objetivos e respostas do jogo e interação. Segundo os autores, a avaliação dos jogos por meio da teoria do Gameflow ajudou os estudantes na criação de seus próprios jogos, já que os mesmos buscaram estratégias de tornar seus jogos mais atrativos, divertidos, não tão

\footnotetext{
${ }^{5}$ Dada a limitação de espaço nesse trabalho não serão exploradas essas heurísticas.
} 
fáceis, nem impossíveis de serem jogados (SHIMOHARA; SOBREIRA; ITO, 2016).

Nunes e Chaves (2017) elaboraram, aplicaram e avaliaram a utilização do jogo digital Ciano Quiz com 55 estudantes do Ensino Médio de uma escola pública de Ribeirão das Neves, Minas Gerais. As autoras exploraram o conteúdo Cianobactérias com o jogo, além de abordarem o tema educação ambiental. Ao final do jogo, os estudantes responderam um questionário pedagógico e outro sobre o conteúdo trabalhado. A maioria dos participantes da atividade proposta por Nunes e Chaves (2017) avaliou positivamente o jogo, indicando que achavam o jogo motivador, interessante e facilitador da aprendizagem. Além disso, a maioria deles avaliou que o Ciano Quiz os fez pensar sobre ações cotidianas que envolvem o meio ambiente e pouco mais de $60 \%$ desses participantes afirmaram ter sentido alto grau de satisfação com o jogo. Sobre as questões que versavam acerca do conteúdo curricular trabalhado, a maioria dos estudantes respondeu de forma correta ou parcialmente correta, conforme avaliação das autoras.

Reis, Leite e Leão (2017) realizaram uma revisão sistemática em onze periódicos da área de ensino, de qualis A1 e A2, entre os anos de 2007 e 2016, avaliando 291 artigos. De acordo com a revisão realizada por Reis, Leite e Leão (2017) acerca da utilização de TIC no ensino de ciências, houve um aumento no número de pesquisas que tratam dessa temática. Entretanto, Reis, Leite e Leão (2017) apontaram que o maior interesse dessas pesquisas se focou em algum material com apoio das TIC, sem preocupações acerca de como o professor trabalha esse material ou de que maneira ele o faz. Os autores indicaram que é preciso investigar estratégias de utilização das TIC no ensino de ciências, considerando a complexidade do processo de ensino e aprendizagem e o protagonismo do professor.

Pesquisando estratégias gamificadas de ensino, Cavalcante, Sales e Silva (2018) investigaram as potencialidades do game Kahoot como ferramenta de avaliação. Para isso, utilizaram o game com 12 estudantes do Ensino Médio de uma escola particular de Fortaleza (CE). Para avaliar a 
eficácia do game eles aplicaram questionário em escala Likert de cinco pontos junto aos estudantes, que analisaram o uso do Kahoot como instrumento avaliativo. Cavalcante, Sales e Silva (2018) afirmam que o game Kahoot é um instrumento avaliativo interessante, por dar resultado imediato, estabelecendo pontuação e ranking entre os alunos. Conforme esses autores, apesar de a maioria dos estudantes não ter conhecido o game anteriormente, todos concordaram, total ou parcialmente, que o mesmo ajuda a estimular a aprendizagem, pois o interesse sobre o conteúdo cresceu a partir do uso da ferramenta.

\section{Os games Code Fred, Simon Cérebro e Comando Imuno}

Os três games trabalhados na investigação foram selecionados segundo um processo de escolha de softwares livres educacionais, partindo do princípio de que esses programas se originam de criação conjunta “(...) para o benefício da coletividade, tendo, portanto a colaboração como modo de construir o conhecimento" (ANDRADE, 2012, p.2). Assim, eles democratizam o acesso ao conhecimento, de forma que a comunidade escolar pode livremente encontrá-los na internet e utilizá-los no processo de ensino e aprendizagem.

De acordo com Fialho e Matos (2010), os softwares educacionais são grandes aliados pedagógicos na metodologia e práxis docente "na arte de envolver o aluno, no constante e rico processo de ensino/aprendizagem" (p.121). Ainda, para Costa e Oliveira (2004), software educacional é aquele projetado especificamente para atender aos objetivos de ensino, que são programados para o aluno aprender acerca de determinado conteúdo.

O game Code Fred pode ser classificado como um game de simulação. Para Alves (2010), esses games "possibilitam aos jogadores experimentar situações que muitas vezes não podem ser concretizadas no cotidiano" (p.210) em que, segundo Valente (1999), o modelo é dado a priori. 
O Code Fred apresenta a complexidade do corpo humano a partir da inter-relação de diversos processos envolvidos em seus sistemas. O game é desenvolvido a partir de uma história em que o Fred é o protagonista. Na trama, o personagem precisa superar diversos perigos/obstáculos - medo, fome, germes - sempre sendo perseguido por um lobo e, a partir de então, diversos processos são desencadeados no seu corpo o que o coloca em alerta e em fuga. Enquanto Fred foge do lobo e enfrenta os perigos, seu corpo é acionado segundo suas necessidades e ações apresentando o funcionamento fisiológico-biológico dos sistemas e processos do corpo humano: sistemas nervoso, endócrino, imunológico, de transporte, digestório, respiratório e coagulação sanguínea.

O game Simon Cérebro foi desenvolvido por meio do projeto Museu Itinerante de Neurociências (MIN), da Organização Não Governamental Ciências e Cognição da Universidade Estadual do Rio de Janeiro (UERJ). O game Simon Cérebro pretende trabalhar o processo de memorização pelo participante, sendo conhecido no Brasil como "Gênius". Ele foi desenvolvido por Cícero Cazé Rabelo e Alfred Sholl-Franco a partir de estudos da neurociência, possibilitando desenvolver, no participante, capacidades mnemônicas. $\mathrm{O}$ game fornece a imagem visual de um cérebro, seccionado em partes coloridas, além de expressão sonora diferenciada quando se clica em cada uma das partes e, nele, o participante deve repetir a sequência apresentada pelo game, que possui uma variedade de combinações.

Já o game Comando Imuno, assim como o Code Fred, se constitui num game de simulação, que faz parte de um projeto de narrativa de ficção científica transmídia ${ }^{6}$, denominado Neuraventura. Desse projeto fazem parte diversas formas de exploração de uma narrativa escrita em diversas mídias: quadrinhos, game, fórum de discussão, blogs, entre outras. O Neuraventura possui o apoio de Ciências e Cognição da Universidade

\footnotetext{
${ }^{6}$ Narrativa com base em partes dispersas de uma história que são apresentadas de forma sistemática através de múltiplas plataformas de mídia. Ver: JENKINS, H. Transmedia storytelling, n. 1, p. 56, 2009.
} 
Estadual do Rio de Janeiro (UERJ), Instituto Claro e da Fundação de Amparo à Pesquisa do Estado do Rio de Janeiro (FAPERJ) e conta com diversos pesquisadores colaboradores. Sua narrativa, envolve o personagem Eduardo, um neurofisiologista, que passeia dentro do sistema nervoso humano para combater a invasão nanotecnológica manipulada por megacorporações que invadem o cérebro humano, a Neuronet, constituída por robôs de tamanho molecular que conseguem penetrar na pele humana. Eduardo, que compõe um grupo de resistência, o Comando Imuno, combate a Neuronet, que produziu um nanorobô de resistência que infectou participantes do próprio grupo, menos Eduardo, imune aos nanorobôs. Este personagem precisa combater os inimigos e desinfetar seus colegas.

Por conta das possibilidades diferentes de utilização desses games nas aulas de Ciências (tanto no aspecto exploração dos conteúdos de Ciências, quanto no fator motivação dos alunos) no âmbito desta pesquisa, os games foram trabalhados com cada turma conforme os assuntos que deveriam ser abordados no período da investigação, conforme indicações da professora de Ciências da escola participante.

\section{Caminhos da pesquisa}

A investigação foi realizada a partir de uma abordagem qualitativa, enfatizando os processos de aprendizagem em sua complexidade e contexto natural, no caso a sala de aula (BOGDAN; BIKLEN, 1994). A pesquisa foi realizada a partir da ação colaborativa/construtiva de três pesquisadores professores da universidade, uma licencianda em Ciências da Natureza, além da professora de Ciências da escola e estudantes de duas turmas de sétima série. Foram envolvidos 45 estudantes das turmas A e B da sétima série do Ensino Fundamental de uma escola da rede privada de ensino, localizada no município de Senhor do Bonfim, Bahia. Desses, 23 estudantes eram da turma A, sendo 13 do sexo feminino e 10 do sexo masculino e 22 estudantes eram da turma $\mathrm{B}$, sendo 14 do sexo masculino e oito do sexo 
feminino. Esses estudantes colaboraram de maneira espontânea e sob a autorização escrita de seus responsáveis, conforme os parâmetros de ética na pesquisa do Conselho Nacional de Saúde, conforme Resolução no 466, de 12 de dezembro de $2012^{7}$.

Todos os alunos dessas turmas foram convidados a participar de uma sequência didática, elaborada para atender aos conteúdos de Ciências que estavam sendo trabalhados pela professora de Ciências.

Os procedimentos seguiram ciclo de aprimoramento da ferramenta de pesquisa (sequência didática) proposta, conforme descrito por Trip (2005), que considera que deve haver o planejamento e reflexão de cada ação (no caso, de cada intervenção didático-pedagógica) que deve nortear a melhoria do instrumento (no caso, a melhoria da sequência didática) para posterior reaplicação. Esse processo de agir-refletir-aprimorar nos direcionou ao aprimoramento da sequência didática após cada reaplicação dela. Dessa forma, a sequência didática que foi aplicada com a turma da $7^{\mathrm{a}} \mathrm{B}$ (chamada de turma B) tinha sido reelaborada a partir de observações verificadas após a realização da intervenção com a turma da $7^{\mathrm{a}} \mathrm{A}$ (denominada turma $\mathrm{A}$ ). Esse processo de reelaboração se deu pela necessidade de aperfeiçoamento do instrumento de ensino: a) a necessidade de incluir mais games além de Code Fred na sequência, já que muitos alunos zeraram rápido demais; b) a necessidade de retirar do planejamento o momento de aula envolvendo expressões da história do game em inglês, o que foi sugerido pelos alunos da turma $\mathrm{A}$, e a não apresentação da história do game previamente à sua exploração, já que os alunos da turma A apontaram que gostariam de ter descoberto sobre o game sozinhos.

Além do mais, com a turma A foi trabalhado unicamente o game Code Fred: survival mode, abordando o assunto Sistema Endócrino Humano. Já a

\footnotetext{
${ }^{7} \mathrm{O}$ projeto que gerou os resultados apresentados nesse artigo, intitulado PLAY CIÊNCIAS: Utilizando softwares educacionais livres para ensinar e aprender ciências foi aprovado pelo Comitê de Ética e Pesquisa - (CEP) da Universidade Federal do Vale do São Francisco (UNIVASF), ad referendum, no dia 04 de junho de 2013. Esse projeto encontra-se registrado sob o $n^{\circ}$ 0010/260613 CEDEP/UNIVASF.
} 
sequência didática da turma B abrangeu, além do Code Fred, os games Simon Cérebro e Comando Imuno, todos eles softwares livres, encontrados na internet. A turma B trabalhou com o conteúdo Sistema Nervoso Humano. Apesar de terem sido selecionados assuntos específicos de ciências para cada uma das turmas envolvidas, foram exploradas a complexidade do corpo humano e a inter-relação entre seus diversos sistemas - isso foi possível porque a professora de Ciências já havia trabalhado outros sistemas do corpo humano anteriormente.

$\mathrm{A}$ intervenção com a turma $\mathrm{A}$ abrangeu quatro encontros, sendo três deles de duas horas cada e um de quatro horas. Já a intervenção com a turma B abrangeu três encontros, sendo dois deles de duas horas cada e um encontro de quatro horas. Todos os episódios de ensino foram gravados em vídeo e posteriormente transcritos.

A sequência de atividades na escola teve o seguinte roteiro: a) apresentação do projeto à comunidade escolar; b) recolhimento de autorização dos responsáveis pelos alunos, pela escola e da professora de Ciências; c) aplicação de atividade de sondagem com a turma, em forma de questionário dissertativo, com todas as questões abertas; d) breve revisão dialógica de conceitos do assunto selecionado; e) aula de inglês, realizada de forma dialógica, abordando palavras, expressões e imagens contidas no game Code Fred (somente para a turma A); f) exploração do(s) game(s) no laboratório de informática da escola; g) entrevistas individuais com os alunos e com a professora de Ciências; h) aplicação de questionário avaliativo, dissertativo, com todas as questões abertas; i) entrevista em grupo focal, com a participação de dez alunos, de ambas as turmas.

Desse modo, para a coleta de dados, além da observação participante, foram aplicadas duas atividades dissertativas do tipo questionário com questões abertas, entrevistas individuais com os alunos e com a professora de Ciências e uma entrevista em grupo focal, conforme apresentado anteriormente. Por meio dos questionários buscou-se conhecer os saberes prévios e posteriores dos alunos acerca dos conteúdos de ciências 
selecionados para pesquisa, além de suas expectativas e sua avaliação acerca do uso dos games na aprendizagem de ciências. Já as entrevistas individuais favoreceram a aproximação dos alunos nos momentos em que interagiam com os games, de modo a conhecer o desenvolvimento de seu pensamento e compreensão acerca do que estava sendo abordado no game. Para Ludke e André (2012), a entrevista suplanta o caráter hierárquico de outros instrumentos de coleta de dados e favorece a interação, momento em que há "influência recíproca entre quem pergunta e quem responde" (p.33). Se houver o estabelecimento de maior aceitação entre o entrevistador e o entrevistado haverá maior aprofundamento e confiança no diálogo (ELLIOT, 2012; LUDKE; ANDRÉ, 2012).

A entrevista em grupo focal propiciou estimular dez alunos participantes (cinco de cada turma) a debater e interagir acerca do aprendizado com os games e as potencialidades atribuídas a ele no processo de ensino e aprendizagem de ciências. Para Elliot (2012), a entrevista em grupo focal incita a participação e o conhecimento das ideias dos participantes, mutuamente. Buscou-se não contaminar os dados dessa entrevista por meio de interferências nas discussões, mas apenas incentivar a participação de todos. Então, essa entrevista grupal teve como objetivo incentivar a exposição de opiniões, inclusive de estudantes mais tímidos e as trocas, evidenciando concordâncias e discordâncias.

A professora de Ciências também cedeu uma entrevista em que avaliou essas potencialidades, já que possui o conhecimento vivencial de saberes expressos por seus alunos e de sua participação nas atividades da sua disciplina.

Os dados obtidos por meio da observação participante e através das respostas aos questionários, além das entrevistas e do grupo focal, foram transcritos, organizados e analisados, mediante análise de conteúdo (BARDIN, 1977). Depois que os dados foram organizados num arquivo de texto, foram realizadas várias leituras, que nos levaram a identificar e destacar todas as informações sobre a temática da pesquisa. Essas 
informações foram reescritas e codificadas, compondo unidades de sentido. Em seguida, as unidades de sentido foram comparadas e classificadas em grupos, tratados como categorias de análise. A partir das categorias buscouse destacar subcategorias, com base no que foi dito pelos discentes e professora entrevistados. Essas categorias, subcategorias e exemplos das falas dos participantes foram alocados em tabelas e interpretados, à luz dos referenciais teóricos estudados.

Para este trabalho, além da indicação dos alunos participantes sobre qual(is) game(s) utilizou(aram) na aula de Ciências (Code Fred, Simon Cérebro ou Neuraventura-Comando Imuno), as percepções deles foram divididas em três grandes categorias: se e por que é possível/positivo aprender ciências por meio de games; o que os participantes percebem como negativo no uso de games para aprender ciências e as contribuições destes games na sua aprendizagem. Essas categorias emergiram dos dados coletados junto aos estudantes e foram subseccionadas em subcategorias, a partir de padrões do que eles afirmaram.

\section{Resultados e Discussão}

Inicialmente, foram observadas as percepções dos alunos sobre se e porque acham possível ou positivo aprender assuntos de Ciências por meio de games. Assim como no caso de Nunes e Chaves (2017), os estudantes tiveram alto grau de satisfação com a utilização dos games, seja por seu aspecto motivador ou facilitador do processo de ensino-aprendizagem. Todos os 45 participantes da presente pesquisa afirmaram que os games são positivos para aprender conteúdos de Ciências, sendo que 37 deles afirmaram que isso ajuda a aprender coisas novas ou aprender mais do assunto proposto. Os mesmos estudantes pontuaram que os games apresentam mais sobre os conteúdos ou oferece modelos explicativos melhores. Conforme afirmou a aluna A18: "Eu acho que aprende mais porque a gente vê as imagens e percebe assim o tanto que é importante o 
corpo humano pra defesa do nosso corpo". Para a aluna A20, na história do game, os modelos apresentados a fez compreender o que deveria fazer para que o corpo de Fred funcionasse corretamente: "eu tenho que dar proteínas aos negócios deles, coração, os músculos porque ele foi comer lixo, aí ficou doente, ele é muito cansado, toda hora ele se cansa" (A20).

Evidenciou-se que o contexto da história, os modelos de órgãos, sistemas e processos propiciaram aos alunos conhecerem os sistemas do corpo por meio de diferentes representações. Os modelos fornecidos pelo jogo, principalmente pelo Code Fred, foram apontados como propiciadores de entendimento sobre como funcionam os sistemas do corpo humano representados: “(...) que é mais fácil aprender jogando, porque a gente está vendo como funcionam as coisas (A9). Eu gostei, eu acho que através do jogo eu tive uma noção de como o sistema endócrino funciona (A10)”.

Revisar conceitos e reforçar a memória foram algumas das explicações às assertivas sobre os games no sentido de facilitar a aprendizagem. Para esses estudantes, os modelos apresentados os levaram a rememorar explicações da professora e ajudar na memorização de ideias. Porém, para A22 foi necessário jogar mais de uma vez para possibilitar a memorização de ideias: “(...) temos que jogar muitas vezes para saber melhor, pois apenas uma vez não tem como lembrar-se de tudo" (A23).

Seis participantes não justificaram porque acreditam ser possível ou positivo aprender ciências por meio do uso de games. Talvez isso seja explicado pela necessidade de explorar melhor as respostas, fazendo perguntas que mobilizem seus processos cognitivos.

Também foi mencionado pelos estudantes que se sentiram motivados a participar da aula por meio do jogo: "Em minha opinião o jogo Code Fred ajuda bastante na nossa aprendizagem, e também ajuda aquelas pessoas que não se interessam a passarem a se interessar" (A19). Para Boruchovitch e Bzuneck (2001), a motivação necessária para a aprendizagem depende de modelagens instrucionais atraentes e adequadas aos alunos, que os estimule e incentive. De acordo com Justi (2010), os modelos de ensino, tais como as 
simulações, gráficos, desenhos, são representações que auxiliam os alunos a compreenderem melhor os modelos curriculares, trazidos pelos livros didáticos, que têm, por sua vez, referência nos modelos científicos. Assim, faz-se importante explorar essas representações, de maneira que os alunos possam observar, refletir e criticar as limitações desses modelos, que não devem ser concebidos como cópias da realidade.

No que se refere aos modelos de sistemas do corpo humano expressos no Game Code Fred, estes apresentam potencialidades que favorecem a percepção de como funcionam e se relacionam diversos processos que acontecem no interior do corpo humano. Entretanto, esses modelos contidos no game também possuem fragilidades que podem conduzir a concepções alternativas errôneas, pois os alunos podem acreditar, por exemplo, que eles sejam reflexos da realidade e não representações da mesma. Ilustrações de jogos e livros não representam exatamente os objetos e fenômenos trabalhados nos conteúdos de ciências, mas são aproximações interessantes e ilustrativas como afirmou o participante A11 em resposta ao questionário: “(...) o Code Fred, foi o que mais eu aprendi, que tinha umas coisas sobre circulação, sobre como pega mais fôlego e como o coração reage com medo". Assim, os modelos didáticos apresentados nos jogos podem propiciar a exploração do aspecto visual da aprendizagem, ilustrando ideias e acontecimentos. É importante que o professor e os estudantes analisem modelos didáticos apresentados refletindo e discutindo aproximações e limites dos objetos e fenômenos reais estudados (JUSTI, 2010).

Dezesseis alunos apontaram o aspecto divertido do game, o que não acontece nas aulas mais corriqueiras. Para eles, os games são mais dinâmicos e é importante trazer brincadeiras para a sala de aula.

Sim, contribui sim, pois ele foca mais o interesse de outros a querer aprender para poder jogar (A7).

(...) ele ajudou muito na minha aprendizagem, o que também é muito divertido e ensina várias coisas sobre o corpo humano (A23). 
Code Fred sim, pois você fica empolgada para jogar e jogando você acaba aprendendo sobre o sistema nervoso. (A18).

Os estudantes envolvidos no estudo de Cavalcante, Sales e Silva (2018) afirmaram que a utilização do game Kahoot como ferramenta de avaliação os motivaram a se interessar mais pelo conteúdo proposto. Talvez esse tipo de efeito envolvente que os jogos eletrônicos exercem sobre os estudantes tenha gerado o aumento do número de estudos que envolvam TIC no ensino de ciências, conforme apurou Reis, Leite e Leão (2017).

Além de apontar o aspecto divertido dos games, um grupo de alunos destacou que o uso de games nas aulas ajuda na cooperação dos colegas, seja porque estimulam o interesse de todos, seja porque para passar de fase é preciso prestar atenção nas aulas para adquirir os saberes necessários. De acordo com Haetinger (2012), para que haja cooperação entre indivíduos essencial, dentre outros elementos, haver objetivos e valores comuns. As aulas envolvendo os games demandaram atenção e cooperação dos estudantes, de modo que todos pudessem ter acesso aos saberes e orientações necessárias para participar da atividade com o jogo. Conforme foi apontado pela estudante A20 na entrevista em grupo focal:

Também tem a questão dos meninos que não prestam atenção na aula, a gente percebeu também que na hora do game eles quiseram mais aprender, porque na aula eles ficam conversando com os outros, no game não. No game eles ficam concentrados para passar de fase e zerar (A20).

A afirmativa anterior coaduna com a assertiva da professora de Ciências: “(...) foi a atenção voltada para o conteúdo, que atentos ao conteúdo teriam a compensação do game, então acho isso o ponto positivo”. Assim, o fator atenção estava relacionado à habilidade de progredir no game. É importante ressaltar que o ato de jogar os motivou a participar ativamente 
na aula e que perceberam que à medida que o faziam, aprendiam sobre os conteúdos curriculares programados.

Assim, a cooperação dos alunos nas atividades com os games pode estar envolvida com o fator motivação, que, segundo Haentiger (2012), depende tanto de fatores intrínsecos ao indivíduo quanto extrínsecos. Para o autor, sem motivação não há interesse e para que esta ocorra é necessário que o aluno se envolva com as atividades didático-pedagógicas. Nesse ponto, o papel do professor é fundamental, buscando garantir, junto a outros sujeitos da comunidade escolar elementos importantes para incentivar o interesse dos estudantes: "Capacidade ou qualidade do meio, da estrutura física, da metodologia, das características de conteúdos e tarefas, da aceitação do grupo e das relações que se estabelecem entre alunos e professores" (HAENTIGER, 2012, p.102).

No caso, o jogo deve motivar a participação inicial dos estudantes, mas o conteúdo precisa ser o foco da atenção dos mesmos no decorrer do processo de ensino e aprendizagem, ou seja, os alunos precisam aprender a gostar de aprender e o game pode ser o desencadeador disso. O processo de ensino e aprendizagem precisa ser associado à sensação de prazer e diversão. No entendimento da motivação aos estudantes suscitada pelos games a teoria do Gameflow pode trazer uma boa contribuição. De acordo com Shimohara, Sobreira e Ito (2016), ao atingir o estado de flow o jogador sente sensação prazerosa com o jogo.

Dois alunos mencionaram que as aulas baseadas somente na leitura do livro didático são cansativas e monótonas e os games oferecem uma maneira diferente de aprender, no estímulo ao interesse do aluno. A professora de Ciências reconheceu as potencialidades dos games nesse sentido, de dinamização da aula: "Eu acho mais apropriado para o reforço para dinamizar mais as aulas, porque durante os games eles precisam estar atentos à parte teórica para conseguir vencer o game se não eles não vão obter sucesso". Além disso, essa professora afirmou que vai utilizar essa estratégia de ensino, possivelmente em parceria com o professor de 
informática. Um dos alunos destacou ainda que os games ajudam a pensar e outros consideraram os aspectos positivos de aprender através dos games, mas não explicaram por quê.

Sobre os aspectos negativos de aprender por meio de games, as opiniões se dividem, em sua maioria: dificuldades em passar de fase no game, a necessidade de existir alguém que medeie a aprendizagem e a não existência de aspectos negativos. Conforme tratado anteriormente, diversas questões precisam ser consideradas ao se escolher um game e utilizá-lo no processo de ensino e aprendizagem, tais como a narrativa expressa no jogo e o equilíbrio entre as capacidades do jogador e o desafio do jogo. Então, a funcionalidade dessa ferramenta dependerá de que tipo de jogador estiver participando da proposta. Nessa questão, foi notado desequilíbrio entre as capacidades de alguns jogadores e os desafios do jogo. Dentre os estudantes participantes, alguns alunos da turma A se sentiram entediados quando zeraram o game Code Fred e não tiveram outros desafios, ainda que a maioria deles tenha aprovado a proposta. Porém, outros colegas da mesma turma não conseguiram zerar o mesmo game. Na turma $\mathrm{B}$, poucos estudantes exploraram os três games propostos, a maioria apenas jogou o game Code Fred e aprovou a proposta.

Também, a professora de Ciências observou que a motivação dos alunos foi fator preponderante para que continuassem a aprendizagem através dos games: "eu percebi que, depois que eles conseguem vencer o game eles não têm mais motivação pra utilizá-los, (...) então acabam perdendo a motivação pra continuar fazendo eles querem procurar por outro poder dinamizar mais". Alguns estudantes apontaram dificuldades em compreender o funcionamento dos games Comando Imuno e Simon Cérebro. Quanto ao Code Fred as maiores dificuldades observadas se relacionam a passar das seguintes fases:

- A fase que trata do transporte do oxigênio dos pulmões aos músculos - essa etapa requer rapidez e percepção do padrão de ação para que as 
hemoglobinas captem as moléculas de oxigênio e as levem até os músculos antes que o tempo se esgote;

- A fase que trata do equilíbrio insulina/glucagon - a maior dificuldade se refere à percepção de como progredir na fase. A maioria dos alunos não percebe que precisam manter a glicemia equilibrada e se distraem com a insulina/glucagon que são liberadas;

- A fase que trata da reconstituição de terminações células nervosas na perna de Fred - os alunos precisam reconstituir as células concomitantemente antes que o tempo se esgote. Muitos alunos decidem reconstituir totalmente uma terminação de cada vez e as demais acabam por definhar.

Conforme exposto, alguns alunos apontaram a necessidade de mediação pedagógica ou afirmaram que é necessário um instrutor para explicar como funciona o game ou se referem à necessidade de aulas expositivas dos conteúdos curriculares antes de jogarem. De acordo com a aluna A8, "Em minha opinião dava (para aprender por meio de games), só que tem que ter um contexto antes, ter uma aula e, depois, o game, não diretamente o game"(grifos nossos).

Em contrapartida, a experiência com o game conseguiu esclarecer questões já trabalhadas e não compreendidas na aula expositiva: "Em questão da sala eu não tinha entendido daquela parte do balanço da insulina e da outra, aquela foi a parte que eu mais aprendi, porque quando a gente perdia a gente ia de novo" (ALUNA B13). Para Filho e Matos (2010):

cada software oferece uma maneira explícita de contribuir com o processo educacional, alguns priorizando apenas a memorização [...], outros favorecendo desafios, testes, análises de dados, levantamento de hipóteses, não exigindo muito a intervenção do professor (p.127). 
O fator autonomia é importante de ser considerado na escolha de um programa de ensino. Assim, na modelagem de um game é preciso que os programadores atentem para esse aspecto, de maneira que os jogadores não sejam dependentes de alguém que já conhece o game. Em contrapartida, outros games têm por objetivo explorar possibilidades dos jogadores aprenderem jogando, incentivá-los a tomar decisões, a arriscarem, a investigarem alternativas de solução de problemas.

Assim, as dificuldades apresentadas pelos estudantes referentes aos desafios propostos pelo jogo podem ser corrigidas por meio de um equilíbrio entre as habilidades dos estudantes e esses desafios, o que poderia ser administrado pela presença de níveis de dificuldades nos games. Esse ponto é mais interessante a ser considerado na utilização dos games no ensino do que o comprometimento do estímulo a autonomia dos estudantes, por meio de intervenção de um adulto a auxiliá-los a passar de fases.

$\mathrm{Na}$ experiência relatada por Shimohara, Sobreira e Ito (2016), a avaliação dos games dos colegas serviram como parâmetro para que cada estudante refletisse sobre a confecção de seu próprio game. Nesse sentido, eles foram autônomos nas decisões tomadas, tanto no aspecto avaliativo, quanto no planejamento e produção de seu jogo. Esse tipo de experiência envolveu o protagonismo dos participantes e os auxiliou a desenvolver habilidades de resolução de problemas, que não se restringem ao espaço escolar, mas são levadas para sua vida cotidiana.

A aluna A17 afirmou que se sentiu nervosa enquanto jogava dada a dificuldade em passar de fase no game Code Fred. É preciso investigar melhor a relação entre games e nervosismo/ansiedade, para saber até que ponto o game pode influenciar negativamente o jogador.

Muitos alunos não encontraram aspectos negativos em utilizar os games para aprender ciências. Já dois alunos avaliaram os games Comando Imuno e Simon Cérebro como difíceis. Apesar de oferecerem informações em português, estas não se mostraram suficientes para que os alunos entendessem o que deviam fazer para jogar ou avançar no game. 
Os fatores vício e violência em games também foram levantados. Entretanto, nenhum aluno afirmou ter se viciado ou encontrar aspectos relativos à violência em qualquer dos games selecionados.

Acerca da utilização dos games poucos alunos afirmaram ter jogado os três. Todos os alunos da turma B jogaram o Code Fred, pois foi o primeiro game apresentado durante a intervenção, apesar de links para os três games terem sido dispostos nas áreas de trabalho dos computadores da escola e os três games terem sido apresentados como atividades a ser exploradas por eles.

Dezesseis alunos indicaram que os games ajudaram a promover a aprendizagem, geralmente relacionando esse fato ao contexto da história oferecida no game. A história de Fred ofereceu um contexto interessante ao aluno para que adentrasse no funcionamento dos sistemas do corpo humano. Muitas vezes os assuntos são trabalhados nas escolas de forma desconexa à realidade cotidiana, interesse ou necessidade dos estudantes. A contextualização no ensino possibilita aproximar o conhecimento escolar dos saberes do aluno, favorecendo a aprendizagem significativa ${ }^{8}$. A ideia da contextualização também foi apontada pelos alunos participantes da pesquisa de Nunes e Chaves (2017), que afirmaram que o jogo Ciano Quiz os auxiliou a pensar acerca de questões ambientais, o que pode levar a mudanças de atitude sobre o meio ambiente.

Alguns alunos destacaram que os games são divertidos e outros deles disseram que os três games contribuíram para sua aprendizagem para não explicaram por quê. Apenas um dos alunos participantes afirmou não ter havido contribuição dos games, pois não conseguiu passar de fase. Assim, de modo geral, a maioria dos estudantes participantes considerou que de alguma forma o game Code Fred contribuiu com sua aprendizagem.

\section{Conclusão}

\footnotetext{
8 Ver em referências Moreira (1999).
} 
A utilização dos games Code Fred, Simon Cérebro e Comando Imuno foi apontada pelos alunos investigados como interessante e importante para auxiliar na aprendizagem dos sistemas endócrino e nervoso humanos. Para eles, o uso de games no ensino de Ciências apreendeu a atenção dos estudantes, facilitou a compreensão do conteúdo além de ser algo divertido, dinâmico e que reduziu a indisciplina na classe. De maneira geral, esses participantes estabeleceram uma relação direta entre o que foi apresentado em classe pela professora e o que foi visto no game, ou então, indutivamente, identificaram processos enquanto jogavam. Uma das alunas afirmou que se sentiu muito nervosa quando não conseguiu passar de fase.

Com base nos dados coletados nesse trabalho é possível, inclusive, sugerir alguns parâmetros de avaliação de games para uso em situações didáticas. Na escolha de um game como apoio ao ensino é importante:

- Observar os modelos da ciência expressos no game e as possibilidades de exploração deles, de maneira que os alunos possam observar, refletir e criticar as limitações desses modelos;

- Buscar games que favoreçam o interesse, a motivação dos alunos, verificando aspectos tais como a qualidade do game, a narrativa envolvida, as características de conteúdos e tarefas presentes nele, a aceitação do grupo e as relações que se estabelecem entre alunos e professores quando jogam;

- Observar se o game possui um nível de dificuldade adequado à turma, que mantenha os alunos envolvidos com o game, mas não os desestimulem ou se o game propõe a existência de níveis de dificuldade que possam ser selecionados pelo jogador;

- Analisar se o game favorece o exercício da autonomia do aluno.

É importante considerar as contribuições positivas do uso de games no ensino de ciências. Porém, faz-se necessário examinar também os possíveis aspectos negativos como a participação mecânica e o desencadeamento de ansiedade e nervosismo através do uso dos games. Destaca-se a necessidade de explorar o quanto a utilização de games pode influenciar no desenvolvimento de ansiedade e nervosismo nos alunos. Além disso, também 
se aponta que essa experiência dele ser replicada com outros grupos e em outros universos de modo a observar e comparar resultados, dada a complexidade do processo educativo.

\section{Agradecimentos}

Agradecemos a Daiane de Jesus Matos por ajudar na coleta e transcrição de dados e a FAPESB pelo financiamento uma bolsa de iniciação científica.

\section{Referências}

ALVES, L. Jogos, Educação e História: novas possibilidades para a geração C. Plurais Revista Multidisciplinar da UNEB. Games e Cultura. Salvador, 1(2), p. 209-225, maio/ago, 2010.

ANDRADE, W. L. S. de. Aprendizagem colaborativa e o uso do software livre na EAD. Anais do IX Encontro Virtual de Documentação em Software Livre e VI Congresso Internacional de Linguagem e Tecnologia Online, 1(1), 2012. Acesso em 06 de Março de 2014. Disponível em http://evidosol.textolivre.org/site/eventosanteriores.

BARDIN, L. Análise de conteúdo. Lisboa: Edições 70, 1977.

BERENGER, M. M.; ELLIOT, L. G.; PARREIRA, A. Grupo Focal. In: ELLIOT, L. G. (org.). Instrumentos de Avaliação e Pesquisa. Rio de Janeiro: Wak Editora, 2012.

BOGDAN, R., e BIKLEN, S. Investigação qualitativa em educação: uma introdução à teoria e aos métodos. Porto, Portugal: Porto Editora, 1994.

BORUCHOVITCH, E.; BZUNECK. J. A. (org.) Motivação do aluno: contribuições da psicologia contemporânea. Petrópolis: Vozes, 2001

CAVALCANTI, A. A.; SALES, G. L.; SILVA, J. B. Tecnologias digitais no Ensino de Física: um relato de experiência utilizando o Kahoot como ferramenta de avaliação gamificada. Research, Society and Development, 7(11), 2018.

CODE FRED: SURVIVAL MODE. Museum of Science + Industry Chicago. Acesso em junho de $2013 . \quad$ Disponível em http://www.msichicago.org/play/codefred/\#.UxeBp84cf7I.

COSTA, J. W. D; OLIVEIRA. M. A. M. (org.) Novas linguagens e novas tecnologias: educação e sociabilidade. Petrópolis: Vozes, 2004. 
ELLIOT, L. G.; HILDENBRAND, L.; BERENGER, M. M. Questionários. In: Elliot, L. G. (org.). Instrumentos de Avaliação e Pesquisa. Rio de Janeiro: Wak Editora, 2012.

FIALHO, N. N.; MATOS, E. L. M. A arte de envolver o aluno na aprendizagem de ciências utilizando softwares educacionais. Educar em Revista, Curitiba, Brasil, n. especial 2, p. 121-136. Editora UFPR, 2010.

GARCEZ, E. S. C. SOARES, M. H. F. B. Um estudo do estado da arte sobre a utilização do lúdico em ensino de química. Revista Brasileira de Pesquisa em Educação em Ciências - RBPEC. v. 17, n.1. Abril 2017. Disponível em: < https://seer.ufmg.br/index.php/rbpec/article/view/2796/3249>. Acesso em: 03 de ago. de 2018.

HAETINGER, M. Aprendizagem criativa: educadores motivados para enfrentar os desafios do novo século: educação a distância, redes de aprendizagem, criatividade e motivação. Rio de Janeiro: Wak Editora, 2012.

JENKINS, H. Transmedia storytelling. 1(1), p. 56, 2009.

JUSTI, R. Modelos e modelagem no ensino de Química. IN: SANTOS, W.L E MALDANER, O.A. (Orgs). Ensino de Química em Foco. Ijuí: UNIJUÍ, p. 368, 2010.

LÉVY, P. Cibercultura. São Paulo: Editora 34, 1999.

LUDKE, M.; ANDRÉ, M. Pesquisa em Educação: abordagens qualitativas. São Paulo: EPU, 2012.

MORAES, M. C. O paradigma educacional emergente. São Paulo: Papirus, 2002.

MOREIRA, M. A. Teorias da aprendizagem. São Paulo: E. P. U, 1999.

NEURAVENTURA - COMANDO IMUNO. Jogo Eletrônico. Ciências e Cognição, UERJ. Acesso em junho de 2013. Disponível em http://cienciasecognicao.org/neuraventura/?page id=314.

NEVES, D. E.; SANTOS, L. G. N. O.; SANTANA, R. C.; ISHITANI, L. Avaliação de jogos sérios casuais usando o método Gameflow. Revista Brasileira de Computação Aplicada, Passo Fundo, v. 6, n. 1, p. 45-59, abr. 2014.

NUNES, P. R.; CHAVES, A. C. L. Ciano quiz: um jogo digital sobre cianobactérias como instrumento para a educação ambiental no ensino médio. Revista Ciências $e$ Ideias, 7(3), Set./Dez., 2016.

PRETTO, N.; PINTO, C. da C. Tecnologias e Novas Educações. Revista Brasileira de Educação, 11, 2006. Disponível em http://www.diaadia.pr.gov.br/ead/arquivos/File/Textos/Pretto.pdf.

REIS, R.; LEITE, B. S.; LEÃO, M. B. C. Apropriação das Tecnologias da Informação e Comunicação no ensino de ciências: uma revisão sistemática da 
última década (2007-2016). RENOTE. Revista Novas Tecnologias na Educação, 15 (2), dez., 2017.

SHAW, G. L. Aprendendo sobre o sistema endócrino humano: superação de obstáculos epistemológicos por meio do game Code Fred. In: VIII Colóquio Internacional de Educação e Contemporaneidade, 2014, São Cristóvão/SE. Anais do VIII Colóquio Internacional de Educação e Contemporaneidade, 2014.

SHAW, G. L.; RIBEIRO, M. S. S. Games no ensino de ciências: desafios e possibilidades. Revasf - Revista de educação da Universidade Federal do Vale do São Francisco, v. 4, p. 75-97, 2014. Disponível em http://periodicos2.univasf.edu.br/index.php/revasf/article/viewArticle/567. Acesso em maio de 2019.

SHAW, G. L.; RIBEIRO, M. S. S. ; ROCHA, J. B. T. Percepções de estudantes sobre games e a aprendizagem de sistemas do corpo humano. In: I Seminário Multidisciplinar sobre Games no Vale do São Francisco, 2014, Petrolina. Anais do I Seminário Multidisciplinar sobre Games no Vale do São Francisco, que ocorreu no Instituto Federal - IFSertão, Petrolina-PE.. Petrolina: Revista Opara, 2014. v. 6. p. 19-24. Disponível em http://revistaopara.facape.br/article/view/166 . Acesso em maio de 2019 .

SHIMOHARA, C.; SOBREIRA, E. S. R.; ITO, O. Potencializando a programação de jogos digitais de matemática através do Scratch e da avaliação Game Flow. In: V Congresso Brasileiro de Informática na educação, 2016, Uberlândia. Anais do Workshop de Informática na Escola, 2016.

SIMON-CÉREBRO. Ciências e Cognição, UERJ. Acesso em junho de 2013. Disponível em http://www.cienciasecognicao.org/min/wpcontent/uploads/2013/05/Simon-Cerebro.swf.

TAJRA, S. F. Informática na Educação: novas ferramentas pedagógicas para o professor na atualidade. $3^{a}$ ed. São Paulo: Editora Érica, 2001.

TAJRA, S. F. Comunidades Virtuais: um fenômeno na sociedade do conhecimento. São Paulo: Érica, 2002.

TRIPP, D. Pesquisa-ação: uma introdução metodológica. Educ. Pesqui., Dez, 31(3), p.443-466, 2005.

Recebido em outubro de 2018.

Aprovado em maio de 2019. 